ORIGINAL RESEARCH PAPER

\title{
CHANGES IN ATTITUDES TOWARDS FOOD ENVIRONMENT IN ROMANIA
}

\author{
TEODOR SALMEN ${ }^{1,2^{*}}$, ROXANA-ELENA BOHILTEA ${ }^{3,4}$, BIANCA-MARGARETA MIHAI $^{4,5}$ \\ MIRELA NEDELESCU ${ }^{5}$, CORINA-AURELIA ZUGRAVU ${ }^{5}$ \\ I “Carol Davila” University of Medicine and Pharmacy Bucharest, Romania \\ ${ }^{2}$ National Institute for Diabetes Mellitus, Nutrition and Metabolic Disorders N. Paulescu, \\ Bucharest, Romania \\ ${ }^{3}$ Department of Obstetrics and Gynecology, "Carol Davila” University of Medicine and \\ Pharmacy Bucharest, Romania \\ ${ }^{4}$ Department of Obstetrics and Gynecology, "Filantropia” Clinical Hospital, Bucharest, \\ Romania \\ ${ }^{5}$ Department of Hygiene and Ecology, "Carol Davila” University of Medicine and Pharmacy, \\ Bucharest, Romania \\ *corresponding author: teodor.salmen@gmail.com
}

Received on 18 November 2021

Revised on 13 December 2021

\begin{abstract}
Attitudes and knowledge regarding the food environment and purchasing behaviour are drivers or hindrances toward a healthier lifestyle. A questionnaire-based study on consumers' knowledge about food and health and main drivers for food purchasing was applied to a group of Romanians and results were compared with those from a similar study carried about 10 years ago. Respondents seem to be more aware of some environmental and ecological problems (deforestation, global warming, etc), about the importance of bioproducts consumption, and regarding the link between food products and health. Still, the nutritional part of the food label is underused. The main reasons for selecting food are the same as in 2011, but with the greater interest paid to food related health aspects and taste. The perceived trust in food safety remains low. The consumers` amount of knowledge regarding food increased, food being perceived more as a useful adjuvant for health maintenance and an energy booster. Ten years after, some positive changes have been noticed in a group of Romanian citizens. Efforts have to continue in order to put a greater accent on the link between health, food, and purchasing behaviour. Education policies at local and European level have to guide consumers' choices so that the impact of food consumption becomes a sanogenic and sustainable one, both on people, and the environment.
\end{abstract}

Keywords: food label, public health nutrition, purchase behaviour, healthy diet

https://doi.org/10.35219/foodtechnology.2021.2.11 


\section{Introduction}

Chronic non-communicable diseases such as obesity or diabetes mellitus are reaching a pandemic proportion worldwide and prevention is an important tool to limit their impact on healthcare systems, improving the patient's quality of life by limiting the development of complications and need for further medical assistance (Swynghedauw, 2019). The first and most important mechanism in order to obtain a healthy life, free of ailments, is to have an adequate nutritional status, which is secondary to adequate knowledge about what you eat including the "skill" of selecting the healthiest food available on the market (Scander et al., 2021; Bohiltea et al., 2019).

Nowadays, nutritional labelling is being used everywhere in Europe and is controlled by regulation 1169/2011, consumers being informed in detail about the composition of what they buy. However, the challenge remains for them to understand and to have the basic knowledge in order to be able to benefit from this comprehensive data provided by labels (Goyal and Deshmukh, 2021). The most sought after influential elements are nutritional factors and their impact on health, but one must not forget that people's choices are made also based on their religion, customs, and preferences (Snehasree et al., 2021; Sunstein, 2021; Iordachescu et al., 2020). The conceptualization of the labels is also important even in the limits of Regulation 1169, in order to not misinform the buyers about their nutritional intake. Generally, reading labels is associated with healthier diets and, as a consequence, healthier consumers (Kliemann et al., 2018; Miller and Cassady, 2015; Anastasiou et al., 2019). Unfortunately, up to now, there is no common definition of portion size in Europe, and a unified one is needed in the future, in order to facilitate the comprehension of nutritional information. The prior customers' amount of nutritional knowledge or the fact that the information from the labels is considered too technical to be understood are essential facts when we want to promote proactively healthy food choices, that prevent chronic diseases (Goyal and Deshmukh, 2021). Beyond labels, an individual's buying behavior is extremely complex, so influencing him in a positive way can be a difficult task. And when we speak about health and food, one must take into consideration also the environmental impact, especially aspects that can be easily influenced by small behavior changes (food waste avoidance, bio food selection, waste recycling, etc).

The present study is integrated in a larger evaluation of the nutritional and lifestyle habits in Romania and aims to identify the main drives for buying a food product, what is the perceived importance of the complex relation food-health and the level of trust in food safety in our country.

\section{Materials and Methods}

A questionnaire-based study took place from August 2019 until June 2020, and results were compared with a similar study carried out 10 years ago (Zugravu et al., 2011), in order to assess the evolution of the Romanian consumers' behavior towards food and food purchasing. The inclusion criterion was age. We included 
Romanians older than 18 years even if they had temporarily worked abroad, of both genders. The questionnaire was distributed both on social media channels (Facebook, WhatsApp, Facebook Messenger, Yahoo Mail) and on paper for responders without internet access; and included a shortened variant of the IFIC questionnaire (www.ific.org) The main questions are presented in table 1. Cronbach`s alpha of the questionnaire was 0.811 , showing good reliability and internal consistency

Table 1. Questions analyzed in the present article and types of answers provided

\begin{tabular}{|c|c|}
\hline $\begin{array}{l}\text { Demographics - age, gender, perceived } \\
\text { economic status, education }\end{array}$ & $\begin{array}{l}\text { Choose from alternatives already } \\
\text { provided }\end{array}$ \\
\hline $\begin{array}{l}\text { Degree of interest in the main environment } \\
\text { and ecological problems such as global } \\
\text { warming, deforestation, pollution }\end{array}$ & $\begin{array}{l}\text { Likert scale for Degree of consideration } \\
\text { (1- Very low degree- } 5 \text { Very high degree) }\end{array}$ \\
\hline $\begin{array}{l}\text { Degree of availability to pay more for } \\
\text { recycling waste }\end{array}$ & $\begin{array}{l}\text { Likert scale for Degree of consideration } \\
\text { (1- Very low degree- } 5 \text { Very high degree) }\end{array}$ \\
\hline $\begin{array}{l}\text { Degree of availability to pay more for bio } \\
\text { food products }\end{array}$ & $\begin{array}{l}\text { Likert scale for Degree of consideration } \\
\text { (1- Very low degree- } 5 \text { Very high degree) }\end{array}$ \\
\hline $\begin{array}{l}\text { Degree of interest regarding the link between } \\
\text { health and food }\end{array}$ & $\begin{array}{l}\text { Likert scale for Degree of consideration } \\
\text { (1- Very low degree- } 5 \text { Very high degree) }\end{array}$ \\
\hline $\begin{array}{l}\text { Degree of consideration of nutritional } \\
\text { information as being contradictory }\end{array}$ & $\begin{array}{l}\text { Likert scale for Degree of consideration } \\
\text { (1- Very low degree- } 5 \text { Very high degree) }\end{array}$ \\
\hline $\begin{array}{l}\text { Reading food labels/term of } \\
\text { validity/nutritional } \\
\text { information/ingredients/being bio }\end{array}$ & Choo \\
\hline \multicolumn{2}{|l|}{ Main reasons for selecting food: } \\
\hline Perceived as accessible to procure & For each reason - Likert scale for degree \\
\hline Perceived as healthier & of agreement $(1-\mathrm{Ve}$ \\
\hline Perceived as accessible as price & high degree) \\
\hline Perceived as healthier & \\
\hline Confidence in food safety & $\begin{array}{l}\text { Likert scale for Degree of agreement with } \\
\text { being safe ( } 1 \text { - Very low degree- } 5 \text { Very } \\
\text { high degree) }\end{array}$ \\
\hline \multicolumn{2}{|l|}{ Main qualities of food in relation to health } \\
\hline $\begin{array}{l}\text { Improve aesthetic aspect } \\
\text { Increase energy level } \\
\text { Maintain health status } \\
\text { Reduce health problems } \\
\text { Reduce risk for health }\end{array}$ & $\begin{array}{l}\text { For each quality- Likert scale for degree } \\
\text { of agreement ( } 1 \text { - Very low degree- } 5 \text { Very } \\
\text { high degree) }\end{array}$ \\
\hline
\end{tabular}

Answers provided had a different form, as shown in Table 1. However, during the final analysis, the 5 points of the Likert scale, where available, were merged into three (low, medium, and high), because of the very low number of respondents in some categories.

The answers to the questionnaire were statistically analyzed by SPSS 14.0 and Microsoft Excel software, using descriptive and chi-square tests as well as the 
graphical representations of the results. The statistical significance cut-off for $\mathrm{p}$ was $<0.05$.

Groups characteristics (2011 versus 2020). If the previous study included 514 respondents, with a mean age of 35 years and a distribution of $60.31 \%$ females and $39.69 \%$ males, the questionnaire distributed between August 2019 and June 2020 included 343 responders, with a mean age of 35.6 years (minimum age 18 years, maximum age 71 years) and a distribution of $81.63 \%$ females and $18.37 \%$ males. The educational level was similar in both groups. The main difference between groups was the income status, which was higher in the 2020 group (chi-square $=$ $39.42, \mathrm{p}<0.001)$.

\section{Results}

We compared both groups `answers, in order to point out changes in attitudes and behaviors.

Interest regarding the main environment and ecological problems such as global warming, deforestation, pollution, etc. was statistically higher in 2020 than in 2011 (Figure 1) (chi-square of 23.23, $\mathrm{p}<0.001$ ).

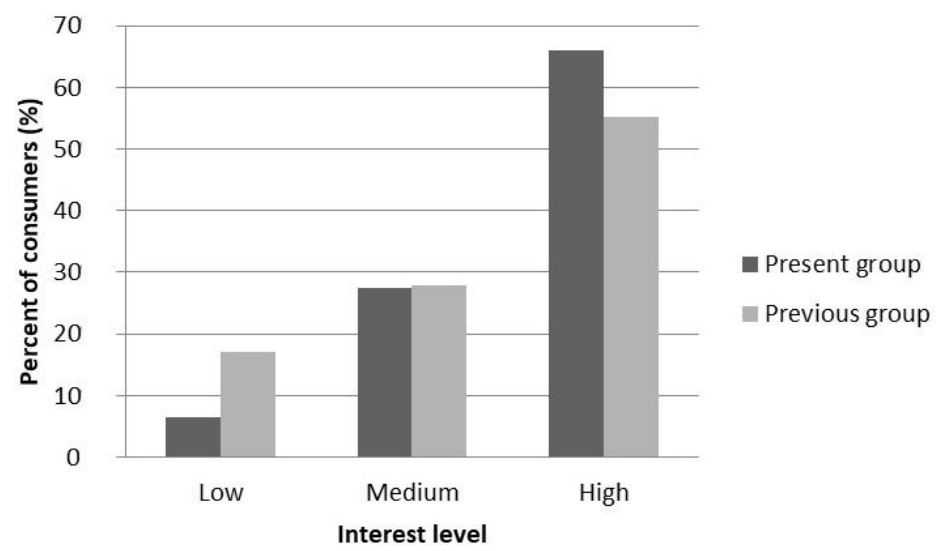

Figure 1. Interest for environmental and ecological problems (global warming, deforestation, pollution, etc.).

The growing interest in environmental and ecological problems is reflected in the availability to pay a higher fee for recycling waste as is shown in Figure 2, with a statistically significant chi-square of $38.225, \mathrm{p}<0.001$.

Moreover, there is a slightly higher availability to pay more for the bio food products (Figure 3), with a statistically significant chi-square of 40.54, $\mathrm{p}<0.001$.

There was also a statistically higher interest for the link between food products and health status (Figure 4) (chi-square $=2.37, \mathrm{p}<0.001$ ). 
The evaluation of nutritional information from different sources as contradictory did not change (Figure 5), (chi-square $=5.99, \mathrm{p}=0.19$ ).

Reading of the label as a whole is similar to the one from ten years ago, differences being non-significant. However, there are some differences regarding the main aspects searched on labels: lesser attention is paid to the ingredients, with a chisquare of 25.7, $\mathrm{p}<0.001$, to calories and nutrients, with a chi-square of 23.23, $\mathrm{p}<0.0001$, and higher attention, to the bio label, with a chi-square of 45.65 , $\mathrm{p}<0.001$, as seen in Table 2 .

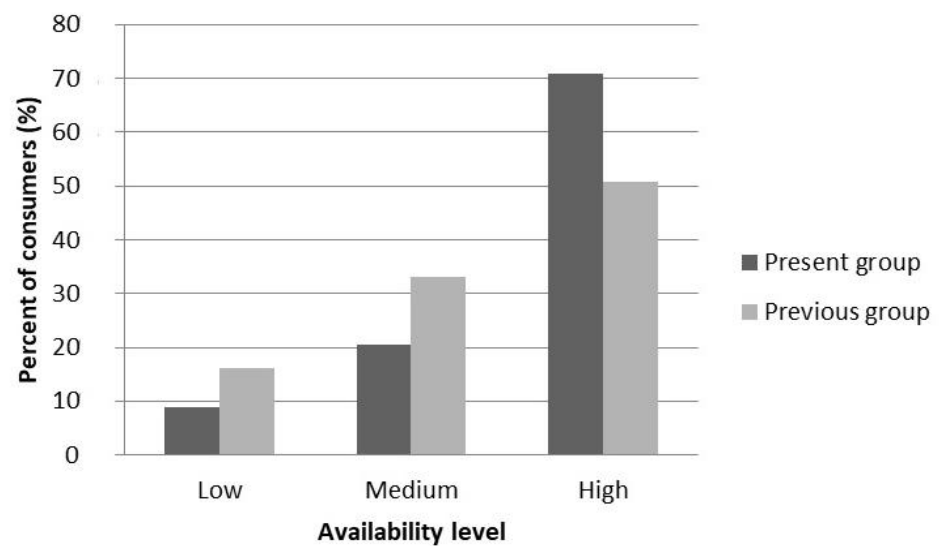

Figure 2. Availability to pay more for recycling waste.

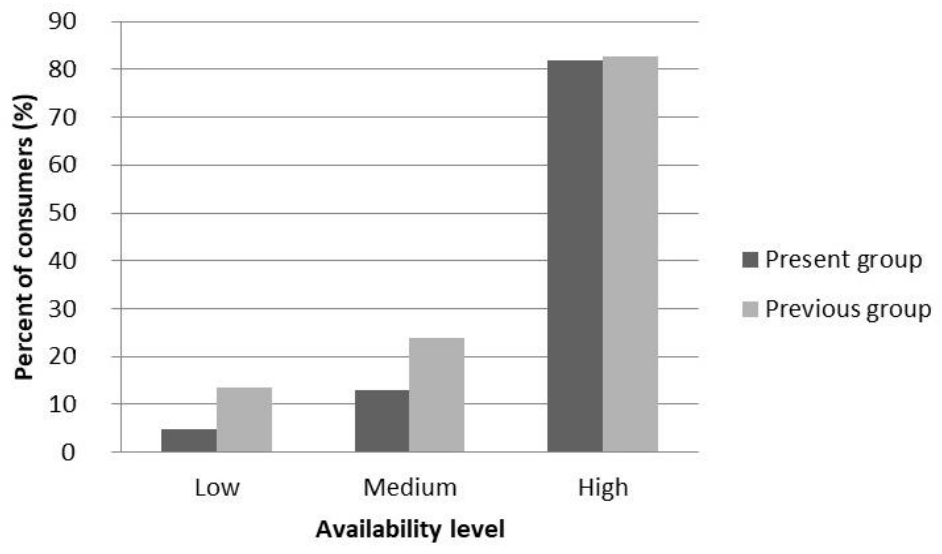

Figure 3. Availability to pay more for bio food. 


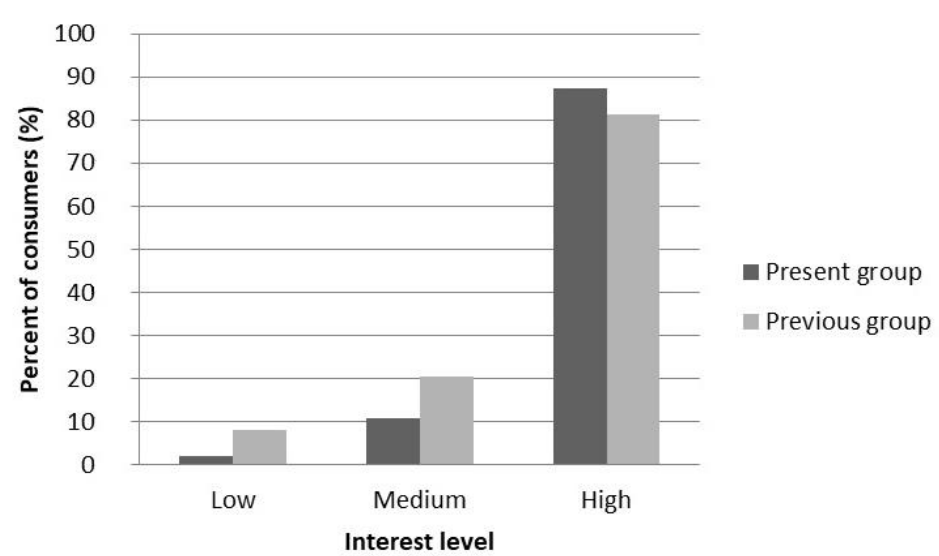

Figure 4. Interest regarding food products`relation to health status.

The main reasons for buying food in 2020, are presented in Figure 6. Compared to 2011, people are more interested in accessibility, healthiness, price, and taste, with statistically significant differences in all items. The main determinants of food purchase remain perceived healthiness and taste.

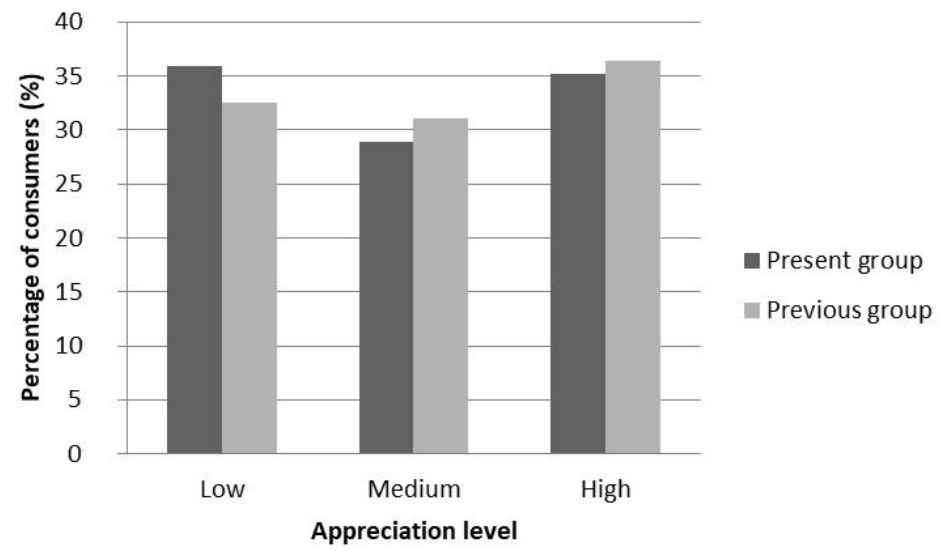

Figure 5. Evaluation of nutritional information as contradicting.

The perceived trust in the safety of the food products is, still, at a low level, with a chi-square of 7.7, $\mathrm{p}=0.102$ (Figure 7).

The consumers` knowledge regarding food`s effects on health is increasing (Figure 8 ). There is a more positive perception of food as contributing to the maintenance of health status (chi-square of 105.7, p<0.001), reducing risks for health (chisquare of 107, $\mathrm{p}<0.001$ ), reducing general health problems (chi square of 140.5, $\mathrm{p}<0.001$ ), increasing energy (chi-square of 156.6, $\mathrm{p}<0.001$ ) and improving "beauty" (aesthetics) (chi-square of 188.7, p<0.001). 
Table 2. Reading food labels behaviour.

\begin{tabular}{|c|c|c|c|c|c|c|}
\hline & \multicolumn{2}{|c|}{ Present group } & \multicolumn{2}{|c|}{ Previous group } & \multirow{2}{*}{$\begin{array}{l}\text { Chi } \\
\text { square }\end{array}$} & \multirow[t]{2}{*}{ P value } \\
\hline & Yes $(\%)$ & No $(\%)$ & Yes (\%) & No $(\%)$ & & \\
\hline Reading labels & 82.3 & 17.7 & 81.1 & 18.9 & 0.03 & 0.85 \\
\hline $\begin{array}{l}\text { Reading the validity } \\
\text { duration }\end{array}$ & 71.8 & 28.2 & 66.9 & 33.1 & 0.58 & 0.44 \\
\hline $\begin{array}{l}\text { Reading information } \\
\text { about calories and } \\
\text { nutrients }\end{array}$ & 46.5 & 53.5 & 78.6 & 21.4 & 23.23 & $<0.0001$ \\
\hline $\begin{array}{l}\text { Reading information } \\
\text { about ingredients }\end{array}$ & 65.7 & 34.3 & 78.6 & 21.4 & 25.7 & $<0.001$ \\
\hline $\begin{array}{l}\text { Checking the bio type } \\
\text { of the products }\end{array}$ & 22 & 78 & 6.4 & 93.6 & 45.65 & $<0.001$ \\
\hline
\end{tabular}

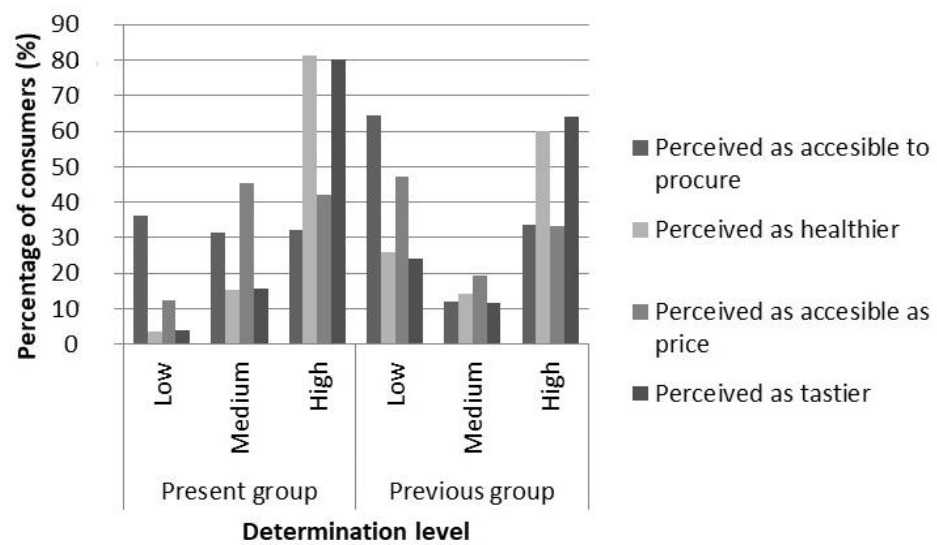

Figure 6. Main determining factors for buying food.

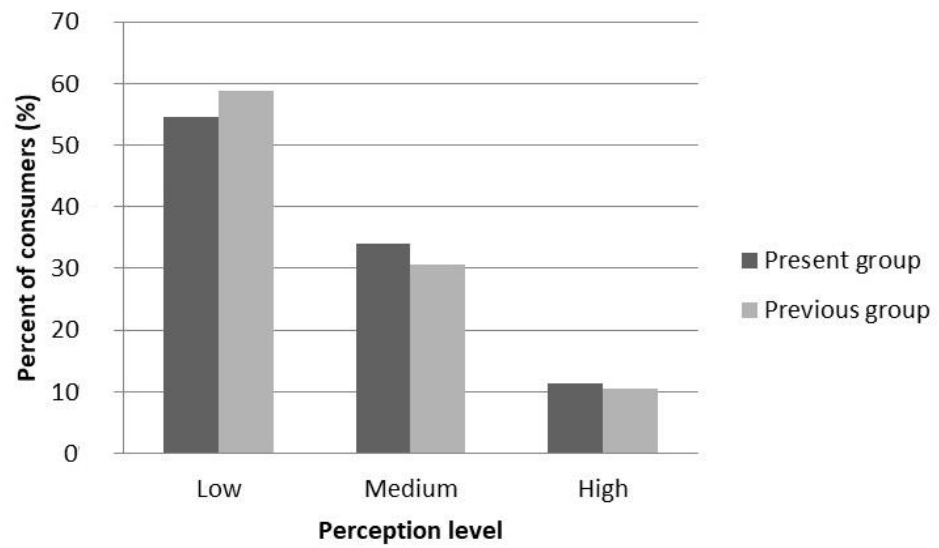

Figure 7. The perceived trust in the safety of food products. 


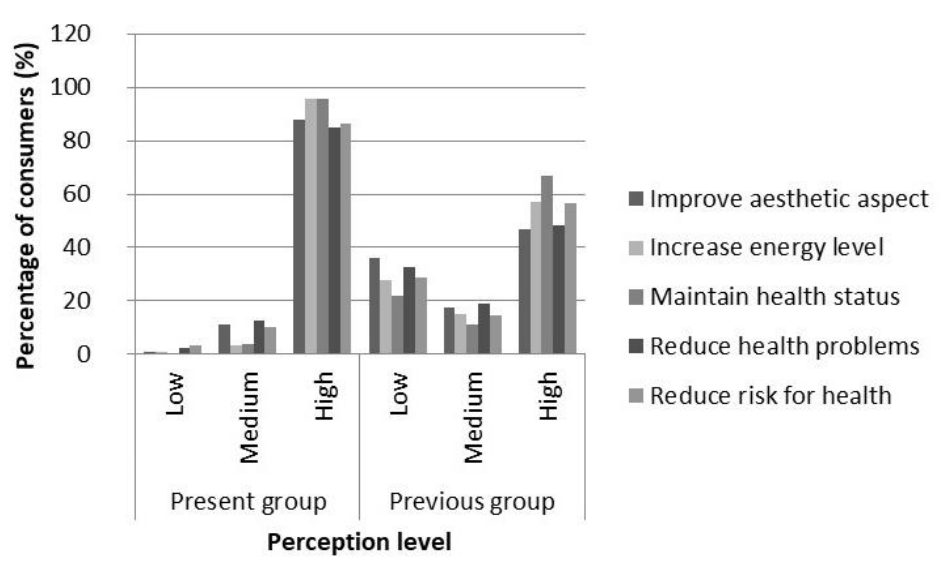

Figure 8. Consumers' perception about food effects.

\section{Discussion}

An increase in the interest in the environment and ecological problems such as global warming, deforestation, pollution, etc., was observed and can be attributed to the informative campaigns covering the influence of the environment on health status, that took place from 2010, initiated by several foundations such as GO GREEN, World Wide Fund for Nature, Green Peace, Mai Mult Verde, Terra Mileniului III. A new European initiative is the European Green Deal, which includes the 'From Farm to Fork' strategy. The strategy aims to obtain food sustainably, by ameliorating the environmental, social, and economic impact of the food systems. It will offer support to the producers, in the process of production and transfer of resources in a climate-friendly efficient approach, with respect for the price and quality of the goods. An emphasis will be paid to reducing the use of chemical pesticides, increasing healthy food options, and offering help to the consumers in order to be able to understand the health benefits of products and sustainable packaging (Tamma et al., 2019; Simon et al., 2019). Moreover, general attention is drawn to the direct connection between what is eaten and its impact on the environment, with emphasis on vegetarian alternatives, far kinder on land, water and carbon emissions (Sanchez-Sabate and Sabaté, 2019).

In our study, the interest for environmental and ecological problems is not only declarative and is reflected in the participant's availability to pay a higher fee for an optional service of waste recycling or to pay more for a bio food product. From 2011, the number of bioproducts consumed increased, as observed by the getbio.ro shop, however remaining a niche on the food market due to the very high prices. The increased interest for bio food is motivated in physically inactive people by the better taste of the products and, respectively, in the physically active people, by their healthier effect (Soroka and Wojciechowska-Solis, 2019). The Farm to Fork strategy of the European Green Deal aims to limit the chemicals from food by providing a sustainable production, processing, distribution, and consumption of 
food, in order to limit loss and waste of food, for obtaining a future environmentfriendly food system (European Committee, 2021).

The similar proportion of appreciation for the nutritional information as being contradictory, noticed in our study despite the numerous health promoting campaigns designed to improve the consumer's way of thinking and ability to make their own informed choices, could be secondary to noncoherent media nutritional facts communication and influence. Rather than remaining true to science, media outlets prefer spectacular reports, but with a greater reach, thus generating higher incomes.

The reading of the nutritional label is present in a similar proportion as previously, with a considerable percentage of consumers reading it before buying a product. It is important to emphasize that the proportion of consumers that read food labels is directly influenced by the amount of nutritional knowledge (Miller and Cassady, 2015).

There is a continuous general effort paid in order to increase the labels' accessibility and visibility. For example, at the European level, the Front of Pack (FoP) labelling system, which is designed to simplify a healthier purchasing decision, is a component of the Farm to Fork Strategy (Temple, 2020). FoP nutritional labelling systems are already implemented: NuVal, Traffic Score, NutriScore or 5-CNL (5-Colour Nutrition Label), Guiding Stars or Health Star Rating system (HSR) (Temple, 2020; Storcksdieck genannt Bonsmann et al., 2020), but there is not a unitary form agreed all over Europe. The intention to implement the FoP System has not yet reached a consensus, because of the disagreement between producers, considering, among others, that a colour key would become a market tool (Southey, 2021). Nutri-Score, a good example of an easy to read FOP, has a system to categorize food between a least healthy and a very healthy category with a letter and a color code: A (healthiest) is being associated with dark green color, while F (least healthy) is associated with dark red color (Temple, 2020; Storcksdieck genannt Bonsmann et al, 2020; Southey, 2021). A study, similar to ours, showed that consumers prefer reading the food labels in order to inform themselves, especially for "best before" date and nutritional aspects (Gomes et al, 2017). On the other hand, another study reported a high percentage of consumers reading food labels, but only half of them really understand what they read (Chopera et al., 2014). So, together with educational campaigns, there is also very important to adapt the food labels to the level of education of the consumers and to make them easier to be read and understood (Jo and Jung, 2019).

In our group, the tendency of reading the details of labels is decreasing for ingredients - a fact explained by the low level of knowledge about the benefits or harms of certain food components or because of a higher interest paid to the taste, rather than to effects on health (Zugravu et al., 2017); and for information about calories and nutrients content, despite the fact that they are easily available now, as compared to the period of the previous study when Regulation 1169 was not yet in force. These are unfortunate findings that raise question marks regarding the efficacy of former and ongoing educational programs. 
On the other hand, as compared to the previous study, there is an incremental, though non-significant, trend in reading other label information such as validity, probably secondary to recent problems with expired food that was forbidden from commercialization, a fact that encouraged the big retailers to implement programmes to limit the food waste.

The central food selection drives remain healthiness and taste. We noted the essential importance of taste, as many food professionals know so well. The novel industrial methods of processing food led to tastier products but with sometimes repercussions on the consumers' health (Chen et al, 2020). Price seems to play a more important role in the food selection of the 2020 sample compared to 2011, maybe due to the decrease in purchasing power noticed especially in the middle class in Romania, underlining the necessity of promoting healthier food for lower prices, in order to make "the healthy choice, the easy choice". One main reason for buying products is still accessibility. Due to urbanisation, the development of hypermarkets, and the busy lifestyle there is the tendency of consumers to choose quickly, under the rule of a momentary impulse, without taking into account the possible negative consequences of their choices.

Trust in the safety of food products remains unfortunately at a low level, finding that can be explained by the low trust in several public entities, including in food regulators and policymakers. Food safety is a topical issue, a fact reflected by the recent scandals, like the one that started in autumn 2020, when in numerous European countries, ethylene oxide was found in sesame seeds from India, starting a huge food recalls chain reaction (Vella, 2020). Consumers need to realize that today there is a particular concern for food safety and that the potential problems are not more numerous than before, but only better brought to the attention of the public.

The level of consumers' knowledge about food and its properties to improve health is on a rise and significantly more 2020 responders consider that food products are generating positive health aspects, such as maintenance of a healthy status, preventing various diseases or usual health problems, improving the physical and psychological energy and performance. It is important to educate consumers about the food-health relation because there is always a connection between what they know and the quality of the products they buy (Trude et al., 2018; Urrialde, 2019).

\section{Conclusions}

After almost 10 years, we have identified some significant changes in the attitude towards the food environment in Romania. Among the positives, even greater attention to the food influence on health as well as an increased interest in environmental issues, including greater availability for recycling and buying organic products are the very important ones. Among the negatives, distrust in food safety, ignoring important elements on food labels, such as nutrition information or ingredients, raise questions about the real sources of information for citizens about the composition of food and its connection to health. The taste remains an 
important drive to food selection, so professionals have to challenge themselves and produce healthier food with a better taste. The education measures implemented so far are not enough and must be continued in a unified and coherent way, aiming to teach the population that the food-health connection has a clear and proven scientific basis. At the same time, a simplified food labelling system is required, in addition to the existing one. What has been done in Romania, up to now, shows positive effects that might be a stimulant for further positive measures.

\section{References}

Anastasiou, K., Miller, M., Dickinson, K. 2019. The relationship between food label use and dietary intake in adults: A systematic review. Appetite, 138, 280-291.

Bohiltea, R.E., Zugravu, C.A., Neacsu, A. 2019. The prevalence of vitamin D deficiency and its obstetrical effects a prospective study on Romanian patients. Revista de Chimie, 70(4), 1228-1233.

Chen, X., Zhang, Z., Yang, H., Qiu, P., Wang, F., Zhao, Q., Fang, J., Nie, J. 2020. Consumption of ultra-processed foods and health outcomes: a systematic review of epidemiological studies. Nutrition Journal, 19, 86.

Chopera, P., Chagwena, D.T., Mushonga, N.G. 2014. Food label reading and understanding in parts of rural and urban Zimbabwe. African health sciences, 14(3), 576-584.

European Committee. Farm to Fork strategy, available at https://ec.europa.eu/food/horizontal-topics/farm-fork-strategy_en, accessed in 16.11.2021.

Gomes, S., Nogueira, M., Ferreira, M., Gregório, M.J. 2017. Portuguese consumers' attitudes towards food labelling. Geneva: World Health Organization.

Goyal, R., Deshmukh, N. 2021. Assessment of knowledge and understanding among consumers regarding food label reading. Journal of Indian Dietetics Association, 40(2), 31-39.

Iordachescu, A.C., Cirstoiu, M.M., Zugravu, C.A. 2020. Dietary behavior during pregnancy. Experimental and Therapeutic Medicine, 20(3), 2460-2464.

Jo, H.S., Jung, S.M. 2019. Evaluation of food labeling policy in korea: analyzing the community health survey 2014-2017. Journal of Korean Medical Science, 34(32), e211.

Kliemann, N., Kraemer, M.V.S., Scapin, T. 2018. Serving size and nutrition labelling: implications for nutrition information and nutrition claims on packaged foods. Nutrients, 10(7), 891.

Miller, L.M., Cassady, D.L. 2015. The effects of nutrition knowledge on food label use. A review of the literature. Appetite, 92, 207-216.

Sanchez-Sabate., R., Sabaté, J. 2019. Consumer attitudes towards environmental concerns of meat consumption: A systematic review. International Journal of Environmental Research and Public Health, 16(7), 1220.

Scander, H., Yngve, A., Lennernäs Wiklund, M. 2021. Assessing commensality in research. International Journal of Environmental Research and Public Health, 18(5), 2632.

Simon, F. 2019. EU Commissions unveils 'European Green Deal': The key points, available at_https://www.euractiv.com/section/energy-environment/news/eu-commissionunveils-european-green-deal-the-key-points/, accessed in 16.11.2021.

Snehasree, S., Subbarao, G., Sudershan, V. 2021. Health and nutrition claims on food labels - means of communication that can influence food choices of adolescents. Journal of Content, Community and Communication, 13, 113-124. 
Soroka, A., Wojciechowska-Solis, J. 2019. Consumer motivation to buy organic food depends on lifestyle. Foods, 8(11), 581.

Southey, F. 2021. Are nutrition labelling schemes a marketing ploy? 'FOPs no longer inform, but influence', available at https://www.foodnavigator.com/Article/2021/01/08/ Are-nutrition-labelling-schemes-a-marketing-ploy, accessed in 17.11.2021.

Storcksdieck genannt Bonsmann, S., Marandola, G., Ciriolo, E., Van Bavel, R., Wollgast, J. 2020. Front-of-pack nutrition labelling schemes: a comprehensive review, EUR 29811 EN, Publications Office of the European Union, Luxembourg.

Sunstein, C. 2021. Viewpoint: Are food labels good? Food Policy, 99, 101984.

Swynghedauw, B. 2019. Age-linked non-transmissible diseases. In: The Biology of Senescence. A Translational Approach. Springer, Cham.

Tamma, P., Schaart, E., Gurzu, A. 2019. Europe's Green Deal plan unveiled, availble at https://www.politico.eu/article/the-commissions-green-deal-plan-unveiled/, accessed in 02.12.2021. POLITICO.

Temple, N. 2020. Front-of-package food labels: A narrative review. Appetite, 144, 104485.

Trude, A.C.B., Surkan, P.J., Cheskin, L.J., Gittelsohn, J. 2018. A multilevel, multicomponent childhood obesity prevention group-randomized controlled trial improves healthier food purchasing and reduces sweet-snack consumption among lowincome African-American youth. Nutrition Journal, 17(1), 96.

Urrialde, R. 2019. Evolución de la información relacionada con la alimentación y la nutrición. Retos de adaptación para y por el consumidor [Evolution of information about feeding and nutrition. Challenges for and by the consumer]. Nutricion Hospitalaria, 36(Spec No3), 13-19. Spanish.

Vella M. 2020. Thousands of foods recalled in year of ethylene oxide 'scandal', available at https://www.maltatoday.com.mt/news/national/111868/thousands_of_foods_recalled_in_ year_of_ethylene_oxide_scandal_\#.YZTFS1VBzIU, accessed in 17.11.2021

Zugravu, C.A., Patrascu, D., Prejbeanu, I., Tarcea, M. 2011. Food label" Check before buy" and association with demographic, nutritional and purchasing factors in a group of Romanians. Food Science and Technology, 12(1), 22-29.

Zugravu, C.A., Pogurschi, E.N., Pătrașcu, D., Iacob, P.D., Nicolae, C.G. 2017. Attitudes towards food additives: A pilot study. The Annals of the University Dunarea de Jos of Galati. Fascicle VI-Food Technology, 41(1), 50-61. 